\title{
Reciprocal regulation of the $\mathrm{Ca}^{2+}$ and $\mathrm{H}^{+}$sensitivity in the Slo1 $\mathrm{BK}$ channel conferred by the RCK1 domain
}

\author{
Shangwei Hou ${ }^{1}$, Rong $\mathbf{X u}^{1}$, Stefan H. Heinemann ${ }^{2}$, and Toshinori Hoshi ${ }^{1}$ \\ ${ }^{1}$ Department of Physiology, University of Pennsylvania, Philadelphia, 3700 Hamilton Walk, \\ Philadelphia, Pennsylvania 19104, USA \\ ${ }^{2}$ Center for Molecular Biomedicine, Department of Biophysics, Friedrich Schiller University Jena, \\ Hans-Knöll-St. 2, D-07745 Jena, Germany
}

\section{Abstract}

Increasing evidence suggests that intracellular $\mathrm{H}^{+}$directly stimulates large-conductance $\mathrm{Ca}^{2+}$ - and voltage-activated $\mathrm{K}^{+}$(Slo1 BK) channels, thus providing a crucial link between membrane excitability and cell metabolism. Here we report that two histidine residues, His365 and His394, located in the intracellular RCK1 domain serve as the $\mathrm{H}^{+}$sensors of the Slo1 BK channel. Activation of the channel by $\mathrm{H}^{+}$requires electrostatic interactions between the histidine residues and a nearby negatively charged residue involved in the channel's high-affinity $\mathrm{Ca}^{2+}$ sensitivity. Reciprocally, His 365 and His394 also participate in the $\mathrm{Ca}^{2+}$-dependent activation of the channel, functioning as $\mathrm{Ca}^{2+}$ mimetics once protonated. Therefore, a common motif in the RCK1 domain mediates the stimulatory effects of both $\mathrm{H}^{+}$and $\mathrm{Ca}^{2+}$, and provides a basis for the bidirectional coupling of cell metabolism and membrane electrical excitability.

Normal functions of excitable cells, such as neurons and muscle cells, critically depend on an intimate and finely tuned regulation of membrane excitability by the cellular metabolic state. The metabolism, in turn, is reciprocally influenced by homeostasis of intracellular ions, and dysregulation of the ion concentrations accompanies many forms of abnormal excitability such as excitoxicity following ischemia/hypoxia ${ }^{1}$ and also in neurodegenerative diseases ${ }^{2}$. Among the intracellular ion species, $\mathrm{Ca}^{2+}$ and $\mathrm{H}^{+}$are particularly important, functioning in an intertwined manner; $\mathrm{H}^{+}$can interfere with numerous $\mathrm{Ca}^{2+}$-dependent processes and alters the intracellular $\mathrm{Ca}^{2+}$ concentration $\left(\left[\mathrm{Ca}^{2+}\right]_{\mathrm{i}}\right)^{3-5}$ and, in turn, alterations in $\left[\mathrm{Ca}^{2+}\right]_{\mathrm{i}}$ modulate the intracellular $\mathrm{H}^{+}$homeostasis ${ }^{6}$.

One of the key coupling mechanisms between the cellular metabolism and electrical excitability is the Slo1 (also known as KCNMA1) BK channel ${ }^{7,8}$. The two distinguishing features of the channel, large conductance and synergic activation by membrane depolarization and intracellular $\mathrm{Ca}^{2+}$, allow the channel to exert a negative feedback influence on cellular excitability under many physiological conditions, especially in neurons and muscle cells ${ }^{9}$. Consistent with this functional role, opening of BK channels often plays a cell-protective role against excitoxicity following hypoxia/ischemic insults 10,11 .

As in other voltage-gated $\mathrm{K}^{+}$channels, four pore-forming Slo1 subunits form a functional BK channel complex, frequently with up to four auxiliary $\beta$ subunits in a tissue-specific manner 12. The transmembrane segments with its $\mathrm{N}$-terminus facing the extracellular side contain the

*To whom correspondence should be addressed. E-mail: hoshi@ hoshi.org.

AUTHOR CONTRIBUTIONS

Designed research: SH, SHH, TH; Performed research: SH, RX, TH; Analyzed data: SH, SHH, TH; Wrote the paper: SH, SHH, TH. 
voltage sensor, and the large cytoplasmic domain is postulated to possess multiple divalent cation sensors within a putative cytoplasmic structured termed a "gating ring", most probably comprised of four sets of dimers made of RCK1 (regulator of conductance for $\mathrm{K}^{+}$) and RCK2 domains ${ }^{13,14}$. The octameric gating ring is considered to expand when $\mathrm{Ca}^{2+}$ binds to the putative high-affinity divalent cation sensor in the RCK1 domain and/or the $\mathrm{Ca}^{2+}$ bowl in the RCK2 domain near the distal C-terminus ${ }^{15}$. This ligand binding then facilitates opening of the channel's gate ${ }^{15}$ perhaps by increasing the tension on the spring-like linker segment between the gate and the RCK domains ${ }^{16}$. While many aspects of the $\mathrm{Ca}^{2+}$-dependent activation of the channel, such as the molecular and biophysical characteristics of the $\mathrm{Ca}^{2+}$ sensors, remain elusive, electrophysiological studies collectively suggest that $\mathrm{Ca}^{2+}$ facilitates activation of the voltage sensor and opening of the gate so that the channel opens more frequently at more negative voltages 15,17 . This allosteric gating of the BK channel is modulated by a variety of intracellular signaling events, and the RCK1/RCK2 domains contain multiple sites critical for modulation of the BK channel such as that by oxidation ${ }^{18}$, heme binding ${ }^{19,20}$, and phosphorylation ${ }^{21}$.

Intracellular $\mathrm{H}^{+}$is also a potent modulator of BK channel function ${ }^{22-24}$. While some conflicting reports exist whether native BK channels are stimulated or inhibited by a decrease in intracellular $\mathrm{pH}\left(\mathrm{pH}_{\mathrm{i}}\right)$, recent evidence shows that, unlike most other $\mathrm{K}^{+}$channels, Slo1 BK channels measured under defined conditions are robustly activated by a decrease in $\mathrm{pH}_{\mathrm{i}}$ near the physiological level ${ }^{22,23}$. This stimulatory effect of low $\mathrm{pH}_{\mathrm{i}}$ may be pathophysiologically significant in early stages of hypoxia/ischemia during which $\mathrm{pH}_{\mathrm{i}}$ typically falls by 0.5 to 1 unit 1. Despite the potential physiological and pathophysiological relevance, the molecular mechanism of the Slo1 BK channel activation by low $\mathrm{pH}_{\mathrm{i}}$ has remained elusive. Our study presented here using human Slo1 BK channels reveals that each Slo1 subunit has a common molecular sensing domain for $\mathrm{Ca}^{2+}$ and $\mathrm{H}^{+}$containing two histidine residues and a negativelycharged residue and that the electrostatic interactions encompassing these residues is altered by $\mathrm{H}^{+}$or by $\mathrm{Ca}^{2+}$ to facilitate opening of the channel. Therefore, the multi-ligand sensor pockets in the Slo1 BK channel provide a direct molecular mechanistic link between the cellular excitability and metabolism.

\section{RESULTS}

\section{Low intracellular $\mathrm{pH}$ activates native and recombinant $\mathrm{BK}$ channels}

The activity of native Slo1 BK channels in rat aortic smooth muscle cells substantially increased when $\mathrm{pH}_{\mathrm{i}}$ was lowered from 7.2 to 6.2 (Fig. 1a). The channel open probability and mean open duration at $-40 \mathrm{mV}$ in the presence of $200 \mathrm{nM}\left[\mathrm{Ca}^{2+}\right]_{\mathrm{i}}$ increased by $13.3 \pm 2.8$ and $3.2 \pm 0.8$ fold, respectively, without any effect on the single-channel current size. In contrast, a decrease in extracellular $\mathrm{pH}$ from 7.2 to 6.2 did not produce any significant effect (data not shown). The stimulatory effect of low $\mathrm{pH}_{\mathrm{i}}$ was observed not only for recombinant human Slo1 (hSlo1) BK channels ${ }^{23}$ but also for Slo1 channels from the fruit fly Drosophila melanogaster (dSlo1) and the cockroach Periplaneta americana (pSlo1; Fig. 1b), suggesting that the underlying molecular machinery is conserved in Slo1 channels from different species and resides in the pore-forming Slo1 $\alpha$ subunit of the BK channel. To identify whether the $\beta 1$ subunit, the predominant type of auxiliary $\beta$ subunits in vascular smooth muscle cells, has any modulating effect, we compared the effects of a $\mathrm{pH}_{\mathrm{i}}$ decrease on heterologously-expressed hSlo1 and hSlo1 $+\beta 1$ channels. A decrease in $\mathrm{pH}_{\mathrm{i}}$ by 1 unit from 7.2 prominently increased the macroscopic hSlo1 and hSlo1 $+\beta 1 \mathrm{~K}^{+}$currents and shifted the conductance-voltage $(\mathrm{G}-\mathrm{V})$ curve to the negative voltage by about $50 \mathrm{mV}$ in both types of channels (Fig. 1c). The simulation effect of $\mathrm{H}^{+}$was concentration dependent with an apparent $\mathrm{EC}_{50}$ of $\sim 0.3\lceil\mathrm{M}$ or $\mathrm{pH} 6.5$ (Fig. 1d) ${ }^{23}$. In addition to the leftward shift in $\mathrm{G}-\mathrm{V}$, lowering $\mathrm{pH}_{\mathrm{i}}$ noticeably accelerated activation kinetics and slowed deactivation kinetics of the channel (Supplementary Fig. 1) ${ }^{23}$. 


\section{Two histidine residues in the RCK1 domain mediate the $\mathrm{H}^{+}$sensitivity}

Activation of Slo1 channels from diverse species by low $\mathrm{pH}_{\mathrm{i}}(\mathrm{Fig} . \mathrm{lb})$ and the previous findings that the leftward $\mathrm{G}-\mathrm{V}$ shift has an $\mathrm{EC}_{50}$ value of $\mathrm{pH}_{\mathrm{i}}=6.5^{23}$ and that the shift is antagonized by the histidine modifier diethyl pyrocarbonate ${ }^{23}$ collectively suggest that the stimulatory effect of low $\mathrm{pH}_{\mathrm{i}}$ is mediated by conserved histidine residues in Slo1 accessible from the cytoplasmic side. Each hSlo1 subunit contains 12 conserved histidine residues, most of which are located in the large cytoplasmic C-terminal domain. In particular, the putative RCK1 and RCK2 domains contain 10 histidines (Fig. 2a). Each of the conserved histidine residues was replaced with arginine and the resulting mutants were assayed for their $\mathrm{pH}_{\mathrm{i}}$ sensitivity using the shift of the G-V curve $\left(\Delta \mathrm{V}_{0.5}\right)$ observed when $\mathrm{pH}_{\mathrm{i}}$ was lowered from 7.2 to 6.2 (Fig. $2 \mathrm{~b}$ ). A decrease in $\mathrm{pH}_{\mathrm{i}}$ from 7.2 to 6.2 in the absence of $\mathrm{Ca}^{2+}$ in the intracellular solution causes a $-50 \mathrm{mV}$ shift in $\mathrm{V}_{0.5}$ for the wild-type channel (Fig. $2 \mathrm{~b}$ ). We found that among the single histidine-to-arginine mutations examined, mutation of His 365 and His394 located in the RCK1 domain significantly diminished the $\mathrm{pH}_{\mathrm{i}}$ sensitivity (Fig. $2 \mathrm{~b}, \mathrm{c}$ ). The $\Delta \mathrm{V}_{0.5}$ value for the mutant $\mathrm{H} 365 \mathrm{R}$ was $-14.0 \pm 1.0 \mathrm{mV}$ and for the mutant H394R, it was $-28.2 \pm 2.0 \mathrm{mV}(P<0.01)$ or about $28 \%$ and $56 \%$ of the shift observed in the wild-type channel, respectively. When the two mutations were present concurrently (H365R:H394R), the $\mathrm{V}_{0.5}$ shift by lowering $\mathrm{pH}_{\mathrm{i}}$ from 7.2 to 6.2 was completely eliminated $(P<0.01)$. A greater decrease in $\mathrm{pH}_{\mathrm{i}}$ to 5.7 and an increase in $\mathrm{pH}_{\mathrm{i}}$ to 7.7 were without any effect (data not shown). Mutation of the two histidine residues to alanine (H365A:H394A) also disrupted the $\mathrm{pH}_{\mathrm{i}}$ sensitivity $(P<0.01)$. Moreover, in these double mutants, the $\mathrm{pH}_{\mathrm{i}}$ decrease failed to alter the kinetics of activation and deactivation (Fig. 2c; Supplementary Fig. 1).

Mutation of His616 located in the putative linker segment between the RCK1 and RCK2 domains (H616R) severely compromised the electrophysiological expression level and we could not obtain any macroscopic currents, even at $300 \mathrm{mV}$ at high $\left[\mathrm{Ca}^{2+}\right]_{i}$. However, singlechannel measurements verified that the mutant $\mathrm{H} 616 \mathrm{R}$ retained a $\mathrm{pH}_{\mathrm{i}}$ sensitivity

indistinguishable from that of the wild-type channel (Supplementary Fig. 2).

To infer about the physicochemical characteristics of His365 essential for the low $\mathrm{pH}_{\mathrm{i}}$ sensitivity of the Slo1 channel, the histidine was substituted with a variety of amino acids. None of the mutants (Arg, Lys, Ala, Asn, Gln, Glu, or Asp at position 365) showed the $\mathrm{pH}_{\mathrm{i}}$ sensitivity comparable to that of the wild-type channel; the $\Delta \mathrm{V}_{0.5}$ values were about $-15 \mathrm{mV}$, only $30 \%$ of the shift observed in the wild-type channel (Fig. 3a, b). Likewise, at position His394, substitution with Arg or Ala equally diminished the $\mathrm{pH}_{\mathrm{i}}$ sensitivity (Fig. 3a, c). The mutagenesis results therefore suggest that the full wild-type like $\mathrm{pH}_{\mathrm{i}}$ sensitivity requires histidine at positions 365 and 394.

The $\mathrm{pK}_{\mathrm{a}}$ value of the imidazole side chain of histidine is often around 6 to 7 and lowering $\mathrm{pH}_{\mathrm{i}}$ from 7.2 to 6.2 is expected to render the side chain positively charged to a greater extent. It may be reasoned that it is the presence of a positive charge at position 365 that in part shifts the voltage dependence of channel activation to the negative direction. According to this idea, $\mathrm{V}_{0.5}$ of the channel with Lys and Arg at position 365 at $\mathrm{pH}_{\mathrm{i}}=7.2$ should resemble that of the wild-type channel with histidine at $\mathrm{pH}_{\mathrm{i}}=6.2$. This prediction is in part born out by comparison of the $\mathrm{V}_{0.5}$ values of the mutants with different amino acids at position 365 at $\mathrm{pH}_{\mathrm{i}}=7.2$ (Fig. $3 d$ ). The $\mathrm{V}_{0.5}$ values in the mutants $\mathrm{H} 365 \mathrm{R}$ and $\mathrm{H} 365 \mathrm{~K}$ were in fact more negative than those of other mutants and similar to that of the wild-type channel at $\mathrm{pH}_{\mathrm{i}}=6.2$. The full $\mathrm{pH}_{\mathrm{i}}$ sensitivity of the Slo1 channel thus requires histidine at positions 365 and 394 and the charge status of the imidazole side chain modulated by $\mathrm{pH}_{\mathrm{i}}$ plays an essential role. 


\section{Electrostatic interactions are involved in the $\mathrm{pH}_{\mathrm{i}}$ sensitivity}

The mutagenesis results led us to hypothesize that an electrostatic mechanism underlies the $\mathrm{pH}_{\mathrm{i}}$-induced activation of the $\mathrm{BK}$ channel; protonated His 365 and His394 in $\mathrm{Slo1}$ at low $\mathrm{pH}_{\mathrm{i}}$ electrostatically interact with nearby residues to facilitate channel activation. To test this idea, the $\mathrm{pH}_{\mathrm{i}}$ sensitivity of the wild-type Slo1 channel was measured using internal solutions with varying ionic strengths; high ionic strength solutions should diminish the negative shift in $\mathrm{V}_{0.5}$ normally observed with lowering $\mathrm{pH}_{\mathrm{i}}$. Consistent with this prediction, the mean $\Delta \mathrm{V}_{0.5}$ value observed on lowering $\mathrm{pH}_{\mathrm{i}}$ from 7.2 to 6.2 became progressively smaller with increasing ionic strengths (Fig. 4a, b).

High ionic strength solutions may slightly increase the $\mathrm{pK}_{\mathrm{a}}$ value of the histidine side chain 25 so that the range of the $\mathrm{pH}_{\mathrm{i}}$ sensitivity of the channel is shifted higher. This possibility can be discounted because increasing $\mathrm{pH}_{\mathrm{i}}$ from 7.2 to 7.7 failed to alter the voltage dependence of the channel activation in both high and normal ionic solutions, indicating that any change in $\mathrm{pK}_{\mathrm{a}}$ of the imidazole side chain by the ionic strength manipulations made a negligible contribution. Addition of sucrose, a non-electrolyte, did not affect the $\mathrm{pH}_{\mathrm{i}}$ sensitivity (data not shown). Taken together, the above results suggest that electrostatic interactions involving His365 and His394 are critical in the $\mathrm{pH}_{\mathrm{i}}$-mediated regulation of the Slo1 BK channel.

\section{Asp367 in the $\mathrm{RCK} 1 \mathrm{Ca}^{2+}$ sensor is important for the $\mathrm{pH}_{\mathrm{i}}$ sensitivity}

A high-resolution atomic structure of the Slo1 channel is not yet available but the amino-acid sequence in the RCK1 domain of Slo1 is relatively similar to that of the bacterial $\mathrm{K}^{+}$channel MthK whose high-resolution structures are known ${ }^{13,26}$. A homology model of the Slo1 RCK1 domain based on an MthK structure ${ }^{7}$ suggests that the two histidine residues critical for the $\mathrm{pH}_{\mathrm{i}}$ sensitivity, His 365 and His394, may be in close proximity of the negatively-charged residues Asp362, Asp367, Asp369, Asp370, Glu374, Glu399, and Asp420 (Fig. 5a). Some of these negatively-charged residues are important for the divalent cation sensitivity of the Slo1 channel, probably forming a high- and a low-affinity divalent cation sensors ${ }^{27-29}$. The possible proximity of His365/His394 to the negatively-charged residues involved in the divalent cation sensitivity suggests that some of these negative charges might be the electrostatic interaction partners of protonated His 365 and/or His394. If so, neutralization of the negatively-charged residues should also disrupt the $\mathrm{pH}_{\mathrm{i}}$ sensitivity of the channel. Neutralization of Glu374, Asp369, Asp370, or Asp420 failed to alter the $\Delta \mathrm{V}_{0.5}$ caused by lowering $\mathrm{pH}_{\mathrm{i}}$ from 7.2 to 6.2 (Fig. 5c). In contrast, $\Delta \mathrm{V}_{0.5}$ was significantly diminished by the triple mutation D362A:D367A:E399A ( $P<0.01$; Fig. 5b, c), which is known to interfere with the $\mathrm{Ca}^{2+}$ sensitivity mediated by the RCK1 domain of the channel ${ }^{27,29}$. Among the three negatively charged residues, only Asp367 plays a critical role in the $\mathrm{pH}_{\mathrm{i}}$ sensitivity of the channel because, when mutated separately, neutralization of Asp367 but not Asp362 or Glu399 noticeably diminished the $\Delta \mathrm{V}_{0.5}$ in response to a decreased in $\mathrm{pH}_{\mathrm{i}}(\mathrm{Fig} .4 \mathrm{~b}, \mathrm{c})$. However, the mutation D367A does not completely eliminate the $\mathrm{pH}_{\mathrm{i}}$ sensitivity, leaving open the possibility that other structural components, including backbone dipoles, electrostatically interact with His365 and His394.

\section{His365 and His394 are also involved in $\mathrm{Ca}^{2+}$-dependence of Slo1}

Our results show that the $\mathrm{pH}_{\mathrm{i}}$ sensitivity of the $\mathrm{Slo1}$ channel requires His365 and His394 as well as Asp367, one of the residues in the RCK1 domain implicated for high-affinity $\mathrm{Ca}^{2+}$ sensing 27,29. The involvement of Asp367 in both the $\mathrm{pH}_{\mathrm{i}}$ and $\mathrm{Ca}^{2+}$ sensing of the channel suggest that His365 and His394 may in turn participate in the channel's $\mathrm{Ca}^{2+}$ sensing. In the wild-type channel, increasing $\left[\mathrm{Ca}^{2+}\right]_{\mathrm{i}}$ to $200 \mu \mathrm{M}$ shifted $\mathrm{V}_{0.5}$ to the negative direction by $\sim 200$ $\mathrm{mV}$ (Fig. 6a). The triple mutation D362A:D367A:E399A, which disrupts the high-affinity $\mathrm{Ca}^{2+}$ sensor in the RCK1 domain ${ }^{27}$, reduces the $\mathrm{V}_{0.5}$ shift caused by $200 \mu \mathrm{M}\left[\mathrm{Ca}^{2+}\right]_{\mathrm{i}}$ by half to $\sim 100 \mathrm{mV}$ with the remaining $\mathrm{Ca}^{2+}$ sensitivity mediated by the $\mathrm{Ca}^{2+}$-bowl segment at the 
distal C-terminus ${ }^{27,29}$. Comparison of the $\Delta \mathrm{V}_{0.5}$ values at different $\left[\mathrm{Ca}^{2+}\right]_{\mathrm{i}}$ (Fig. 6a) showed that the two histidine double mutants H365R:H394R and H365A:H394A, neither of which showed any appreciable $\mathrm{pH}_{\mathrm{i}}$ sensitivity, also had noticeably diminished sensitivity to $\left[\mathrm{Ca}^{2+}\right]_{\mathrm{i}}$; the $\mathrm{V}_{0.5}$ shift by $200 \mu \mathrm{M}\left[\mathrm{Ca}^{2+}\right]_{\mathrm{i}}$ was about $100 \mathrm{mV}$ or $50 \%$ of that found in the wildtype channel. The dependence of $\mathrm{V}_{0.5}$ on $\left[\mathrm{Ca}^{2+}\right]_{\mathrm{i}}$ in the $\mathrm{pH}_{\mathrm{i}}$-insensitive histidine mutants in fact closely resembled that of the triple mutant D362A:D367A:E399A with the disrupted $\mathrm{RCK} 1 \mathrm{Ca}^{2+}$ sensor.

In addition to $\mathrm{Ca}^{2+}$, intracellular $\mathrm{Mg}^{2+}$ also activates the Slo1 channel, and Glu374 and Glu399 in the RCK1 domain, potentially near His365 and His394 (Fig. 6b), form a low-affinity divalent cation-sensing site that transduces alterations in $\left[\mathrm{Mg}^{2+}\right]_{\mathrm{i}}{ }^{27-29}$. Therefore, we examined whether His365 and His394 are involved in the channel's low-affinity divalent cation ion sensitivity. The $\mathrm{Mg}^{2+}$-dependent activation of the double mutant H365R:H394R was indistinguishable from that of the wild-type channel (Fig. 6b). Similar results were also obtained with the double mutant H365A:H394A (data not shown).

\section{DISCUSSION}

Slo1 BK channels constitute an important element linking cellular metabolism and membrane excitability in part because of the synergic activation by intracellular $\mathrm{Ca}^{2+}$ and membrane depolarization. Recent results have shown that Slo1 BK channels are also activated by intracellular $\mathrm{H}^{+}$, a key regulator of cellular metabolism, thereby providing an additional coupling pathway between cell metabolism and membrane excitability. Here we have elucidated the mechanism of such signaling linkage provided by the Slo1 channel and intracellular $\mathrm{H}^{+}$. Two histidine residues, His365 and His394 located in the RCK1 domain are essential for the $\mathrm{pH}_{\mathrm{i}}$ sensitivity of the Slo1 BK channel. Protonated His365 and His394 electrostatically interact with Asp367 and potentially with other charged residues and/or dipoles to selectively transduce changes in $\left[\mathrm{Ca}^{2+}\right]_{\mathrm{i}}$ and $\left[\mathrm{H}^{+}\right]_{\mathrm{i}}$ to allosterically facilitate opening of the channel gate.

The mutagenesis results presented here suggest that histidine with the imidazole side chain at positions 365 and 394 is the only naturally occurring amino acid that supports the $\mathrm{pH}_{\mathrm{i}^{-}}$ dependent activation of the Slo1 channel. Furthermore, substitution of His365 and His394 with arginine or lysine alters the voltage dependence of the channel at normal $\mathrm{pH}_{\mathrm{i}}$ to resemble that of the wild-type channel at low $\mathrm{pH}_{\mathrm{i}}$ at which His 365 and His394 are expected to be protonated. These observations together show that His 365 and His 394 represent the primary $\mathrm{H}^{+}$sensors of the channel required to facilitate its activation.

The $\mathrm{H}^{+}$sensors His365 and His394, when protonated, electrostatically interact with Asp367 as evidenced by the results of the ionic strength manipulations and the charge-neutralization mutation of aspartic acid at position 367. The exact spatial arrangement of these interacting residues is not yet clear because of the lack of detailed structural information. However, the residues are likely to be arranged within $\sim 10$ to $15 \AA$ of each other based on the typical effective range of long-distance electrostatic interactions ${ }^{30}$. A homology model of the Slo1 RCK1 domain developed by Latorre and Brauchi ${ }^{7}$ (Fig. 5a) suggests a distance of $\sim 7 \AA$ between the side chains of His365 and Asp367 and of $\sim 20 \AA$ between those of His394 and Asp367.

In addition to Asp367, other charged residues and/or dipoles, such as carbonyl oxgens, must electrostatically interact with His365 and His394 for neutralization of Asp367 alone eliminate only $\sim 50 \%$ of the $\mathrm{pH}_{\mathrm{i}}$ sensitivity. Asp367 is part of the high-affinity divalent cation sensor in the RCK1 domain of the channel, which under physiological conditions, transduces $\left[\mathrm{Ca}^{2+}\right]_{\mathrm{i}}$ 27,29. Therefore, we suggest that His365, His394 and Asp367 form a bi-functional ligand- 
sensing subdomain for intracellular $\mathrm{H}^{+}$and $\mathrm{Ca}^{2+}$ such that mutation of the aforementioned residues alters the sensitivity to both $\mathrm{H}^{+}$and $\mathrm{Ca}^{2+}$.

The electrostatic mechanism of the $\mathrm{H}^{+}$-dependent activation of the channel involving His 365 and His394 provides unexpected insights into the properties of the high-affinity divalent cation sensor in the RCK1 domain. Mutation of Asp367 or Met513 in this domain interferes with the overall high-affinity divalent cation sensitivity of the channel ${ }^{27,29,31}$; however, complete and detailed characteristics of the sensors have not been elucidated. Our study here shows that the two histidines residues are integral components of the high-affinity divalent cation sensor. The electrostatic interaction of the protonated side chains of His 365 and His394 with Asp367 at low $\mathrm{pH}_{\mathrm{i}}$ functionally and partly mimics the interaction of $\mathrm{Ca}^{2+}$ with Asp367; $\mathrm{H}^{+}$of the His $365 /$ His394 imidazole side chain acts as a $\mathrm{Ca}^{2+}$ mimic for Asp367. The contributions of His365 and His394 to the $\mathrm{H}^{+}$-dependent activation of the channel may be energetically independent of each other because the effects of the His 365 and His 394 mutations on the voltage dependence are additive. This conclusion must be considered somewhat tentative, however, because multiple gating transitions contribute to determination of the data description parameter $\mathrm{V}_{0.5}$.

While both $\mathrm{H}^{+}$and $\mathrm{Ca}^{2+}$ shift the voltage dependence of the channel to the negative direction, thus providing a stimulatory influence on the channel, some differences in their actions on the channel do exist. The maximal shift in the voltage dependence induced by high concentrations of $\mathrm{Ca}^{2+}$, about $-200 \mathrm{mV}$, is appreciably larger than that by $\mathrm{H}^{+}$. This difference occurs because the overall high-affinity $\mathrm{Ca}^{2+}$ sensitivity of Slo1 arises from two distinct but relatively equipotent sensors, the RCK1 sensor and the $\mathrm{Ca}^{2+}$ bowl ${ }^{32}$, while the $\mathrm{H}^{+}$sensitivity is mediated only by the RCK1 sensor. The $\mathrm{Ca}^{2+}$ bowl does not contribute to the $\mathrm{H}^{+}$sensitivity, thus further illustrating functional differences between the two high-affinity $\mathrm{Ca}^{2+}$ sensors. Even within the RCK1 Ca ${ }^{2+} / \mathrm{H}^{+}$sensor subdomain, clear functional specializations are observed. For example, His365, His394 and Asp367 transduce both $\mathrm{Ca}^{2+}$ and $\mathrm{H}^{+}$but Asp362 near the high-affinity $\mathrm{Ca}^{2+}$ sensor in the RCK1 domain ${ }^{27,29}$, does not contribute to the $\mathrm{pH}_{\mathrm{i}}$ sensitivity. The true binding affinity of the subdomain to $\mathrm{H}^{+}$and $\mathrm{Ca}^{2+}$ is not known, but the $\mathrm{EC}_{50}$ values of the channel activation for $\mathrm{H}^{+}$and $\mathrm{Ca}^{2+}$ based on ionic current measurements are about $0.35 \mu \mathrm{M}$ 23 and $\sim 10 \mu \mathrm{M}^{33}$, respectively, suggesting that the Slo1 channel may be considered more sensitive to $\mathrm{H}^{+}$than to $\mathrm{Ca}^{2+}$.

The cytoplasmic gating ring domain of the Slo1 is considered to be structurally similar to that of the prokaryotic channel $\mathrm{MthK}{ }^{14,34}$. Yet, in clear contrast to the $\mathrm{H}^{+}$-stimulated gating of Slo1 described here, the MthK channel activity is profoundly inhibited by $\mathrm{H}^{+26}$. At low $\mathrm{pH}_{\mathrm{i}}$ (e.g., 6.2), the gating ring of MthK disassembles into four dimers ${ }^{35}$ and the channel fails to open, even in the presence of $10 \mathrm{mM}\left[\mathrm{Ca}^{2+}\right]^{26}$. In the Slo1 channel, $\mathrm{H}^{+}$essentially acts as a $\mathrm{Ca}^{2+}$ mimetic for the RCK1 Ca ${ }^{2+}$ sensor and it is highly unlikely that the Slo1 gating ring structure undergoes $\mathrm{pH}$-dependent assembly and disassembly as observed in the MthK channel. The $\mathrm{pH}_{\mathrm{i}}$-sensitivity of $\mathrm{MthK}$ has been suggested to require His 193 located in its otherwise hydrophobic octamer assembly interface ${ }^{26}$. His 193 is poorly conserved among RCK domains 26 and it is equivalent to M442 in the Slo1 channel ${ }^{34}$, distinct from His 365 and His394 required for the $\mathrm{H}^{+}$-stimulated gating. Conversely, the residues equivalent to His365 and H394 do not exist in MthK (Fig. 2a). Thus, while MthK and Slo1 share a similar cytoplasmic structural organization, the two channels employ distinct mechanisms to transduce intracellular $\mathrm{pH}$.

The high sensitivity of the Slo1 $\mathrm{BK}$ channel to changes in $\mathrm{pH}_{\mathrm{i}}$ renders this channel very well suited for coupling membrane excitability/neuronal transmission and cellular metabolism. The cellular metabolic state and $\mathrm{pH}_{\mathrm{i}}$ are intimately and reciprocally linked, and $\mathrm{H}^{+}$may be viewed as a metabolic intracellular messenger 36,37 . Accordingly, the $\mathrm{H}^{+}$and $\mathrm{Ca}^{2+}$ sensitivity of the Slo1 BK channel conferred by His365, His394 and Asp367 is likely to have physiological implications. Fluctuations in $\mathrm{pH}_{\mathrm{i}}$, under both physiological and pathophysiological conditions, 
are typically accompanied by changes in $\left[\mathrm{Ca}^{2+}\right]_{\mathrm{i}}$. For example, intense neuronal firing leads to a noticeable decrease in $\mathrm{pH}_{\mathrm{i}}{ }_{\mathrm{i}}^{6,38}$. Pathophysiologically, malignant hyperthermia and hypercapnia decrease $\mathrm{pH}_{\mathrm{i}}{ }^{39,40}$. Furthermore, cerebral ischemia decreases $\mathrm{pH}_{\mathrm{i}}$ rapidly within a few minutes from by 0.5 to 1 unit $^{1}$, large enough to noticeably activate Slo1 BK channels. Concurrently with the increase in $\left[\mathrm{H}^{+}\right]_{\mathrm{i}}$, ischemia frequently causes a substantial increase in $\left[\mathrm{Ca}^{2+}\right]_{\mathrm{i}}$, in part through activation of $\mathrm{Ca}^{2+}$-permeant glutamate receptor channels, possibly leading to excitoxicity ${ }^{41}$. Increases in both $\left[\mathrm{H}^{+}\right]_{\mathrm{i}}$ and $\left[\mathrm{Ca}^{2+}\right]_{\mathrm{i}}$ activate Slo1 BK channels, but the two ligand-dependent activation mechanisms may play differential roles in blunting the extent of hyperexcitability caused by $\mathrm{Ca}^{2+}$. It may be speculated that the $\mathrm{H}^{+}$-mediated activation of the Slo1 BK channel has a feed-forward anticipatory role while the $\mathrm{Ca}^{2+}$ dependent activation of the channel has a feedback role in regulation of the membrane excitability.

$\mathrm{K}^{+}$channels are an exceptionally diverse family of ion channels. However, only a very small number of the channels are activated by intracellular $\mathrm{H}^{+}$. TREK-1, a two-pore domain voltageindependent leak $\mathrm{K}^{+}$channels with four transmembrane segments, is one example ${ }^{42}$. Among the voltage-dependent $\mathrm{K}^{+}$channels, the Slo1 BK channel is unique in that intracellular $\mathrm{H}^{+}$ enhances its ionic current ${ }^{22,23}$. Both the permeation and gating properties of the Slo1 channel are well suited to transduce changes in $\mathrm{pH}_{\mathrm{i}}$. As shown in this study, low $\mathrm{pH}_{\mathrm{i}}$ prominently shifts the voltage dependence of activation to the negative direction to facilitate channel opening. Furthermore, unlike most other $\mathrm{K}^{+}$channels, the single-channel conductance of the Slo1 channel, especially at physiological voltages, is resistant to pore blocking by intracellular $\mathrm{H}^{+43}$. In Shaker and other voltage-gated $\mathrm{K}^{+}$channels, lowering $\mathrm{pH}_{\mathrm{i}}$ to 6.4 decreases the singlechannel current size by about $50 \%$ without affecting their voltage dependence of activation ${ }^{44}$. The unusual $\mathrm{H}^{+}$-activated gating based the electrostatic interactions encompassing histidine and aspartic acid residues in the RCK1 domain and the $\mathrm{H}^{+}$-resistant permeation characteristics of the Slo1 BK channel contribute to its role as an important coupling mechanism between the cell metabolic state and membrane excitability ${ }^{8}$. To serve a variety of physiological needs, cells express a diverse complement of $\mathrm{K}^{+}$channels, most of which are inhibited by $\mathrm{H}^{+}$.

Inclusion of Slo1 BK channels activated by $\mathrm{H}^{+}$and $\mathrm{Ca}^{2+}$ in the proteome permits fine-tuning of the membrane excitability according to their metabolic state.

\section{METHODS}

\section{Channel expression and cell isolation}

Human (KCNMA1; U11058), Drosophila (M96840) 45 and Periplaneta Slo1 (AF452164)

45 in the expression vectors pCI-neo (Promega), pcDNA3 (Invitrogen) and pcDNA3, respectively, were transiently expressed in HEK tsA cells using FuGENE 6 (Roche) as described 19. In some experiments, human Slo1 and $\beta 1$ (KCNMB1; U38907) in pEGFP-N1 (Clontech) with 1:1 weight ratio were transfected together. We constructed the mutant channels using a PCR-based mutagenesis method (Stratagene). Other constructs used are described in the legends. Cultured rat aortic smooth muscle cells were prepared as described 46.

\section{Electrophysiology and data analysis}

Macroscopic and single-channel ionic currents were recorded from excised inside-out membrane patches at room temperature ${ }^{19}$. Patch electrodes (Warner) had a typical resistance of $1.5-2.0 \mathrm{M} \Omega$ and the series resistance, $90 \%$ of the initial input resistance, was electronically compensated in macroscopic current measurements. Macroscopic capacitive and leak currents were subtracted using a $P / 6$ protocol. The current signal was filtered at $10 \mathrm{kHz}$ through the built-in filter of the patch-clamp amplifier (AxoPatch 200A; Axon) and digitized at $100 \mathrm{kHz}$ using an ITC-16 AD/DA interface (Instrutech). The results were analyzed as previously described using IGOR Pro (Wavemetrics) ${ }^{19}$. Statistical comparisons were performed using 
the unpaired or paired $t$ test, as appropriate. Comparison of more than two groups was performed using ANOVA followed by a Tukey HSD test ${ }^{47}$ as implemented in IGOR Pro. Statistical significance was assumed at $P \leq 0.05$ and all data are presented as mean \pm s.e.m.

\section{Solutions}

The extracellular solution for rat aortic smooth cells contained (in $\mathrm{mM}$ ): $134 \mathrm{NaCl}, 6 \mathrm{KCl}, 1$ $\mathrm{MgCl}_{2}, 2 \mathrm{CaCl}_{2}, 10$ Glucose, 10 HEPES, $\mathrm{pH} 7.4$ with $\mathrm{NaOH}$. The extracellular solution for HEK tsA cells contained (in mM): $140 \mathrm{KCl}, 2 \mathrm{MgCl}_{2}, 10$ HEPES, pH 7.2 with $N$-methyl- $D$ glucamine (NMDG). To compare Slo1 currents at different $\mathrm{pH}_{\mathrm{i}}$ in the virtual absence of $\mathrm{Ca}^{2+}$, the intracellular solution contained (in $\mathrm{mM}$ ): $140 \mathrm{KCl}, 11$ EDTA and either 10 HEPES (NMDG) for $\mathrm{pH}_{\mathrm{i}} 7.2$ or $10 \mathrm{MES}(\mathrm{NMDG})$ for $\mathrm{pH}_{\mathrm{i}} 5.7,6.2$ and 6.7. These solutions were assumed to have $\left[\mathrm{Ca}^{2+}\right]=10 \mathrm{nM}^{48}$. EDTA was selected because its chelating ability is less sensitive to changes in $\mathrm{pH}$ than EGTA. BAPTA was not used in the study as it may have a direct blocking action on the Slo1 channel ${ }^{23}$. The concentrations of NMDG in the above internal solutions were from 3 to $20 \mathrm{mM}$ and, at these concentrations, no effect on the Slo1 channel activity was observed. Free $\mathrm{Ca}^{2+}$ concentrations $\left(\left[\mathrm{Ca}^{2+}\right]\right)$ were calculated using Patcher's Power Tools for Electrophysiologists (http://www.mpibpc.gwdg.de/abteilungen/140/software/). The $\mathrm{pH}=7.2$ solutions with different $\left[\mathrm{Ca}^{2+}\right]$ were prepared as descried ${ }^{49}$ using EGTA or EDTA (for $\left[\mathrm{Ca}^{2+}\right]=\sim 10 \mathrm{nM}$ (no added $\left.\left.\mathrm{Ca}^{2+}\right)\right)$, HEDTA $\left(\left[\mathrm{Ca}^{2+}\right]=200 \mathrm{nM}-5 \mu \mathrm{M}\right)$ or without any chelator $\left(\left[\mathrm{Ca}^{2+}=\right] \geq 200\right.$ $\mu \mathrm{M})$.

\section{Supplementary Material}

Refer to Web version on PubMed Central for supplementary material.

\section{Acknowledgments}

We thank Dr. M. L. Garcia for the original Slo1 construct and Drs. Latorre and Brauchi for the structural model. Supported in part by NIH and SFB 604 (TP A4).

\section{References}

1. Lipton P. Ischemic cell death in brain neurons. Physiol Rev 1999;79:1431-568. [PubMed: 10508238]

2. Kann O, Kovacs R. Mitochondria and neuronal activity. American journal of physiology 2007;292:C641-57. [PubMed: 17092996]

3. Higo T, et al. Subtype-specific and ER lumenal environment-dependent regulation of inositol 1,4,5trisphosphate receptor type 1 by ERp44. Cell 2005;120:85-98. [PubMed: 15652484]

4. Austin $\mathrm{C}$, Wray $\mathrm{S}$. Interactions between $\mathrm{Ca}^{2+}$ and $\mathrm{H}^{+}$and functional consequences in vascular smooth muscle. Circ Res 2000;86:355-63. [PubMed: 10679489]

5. Yao H, Haddad GG. Calcium and $\mathrm{pH}$ homeostasis in neurons during hypoxia and ischemia. Cell Calcium 2004;36:247-55. [PubMed: 15261480]

6. Chesler M. Regulation and modulation of $\mathrm{pH}$ in the brain. Physiol Rev 2003;83:1183-221. [PubMed: 14506304]

7. Latorre R, Brauchi S. Large conductance $\mathrm{Ca}^{2+}$-activated $\mathrm{K}^{+}(\mathrm{BK})$ channel: activation by $\mathrm{Ca}^{2+}$ and voltage. Biological research 2006;39:385-401. [PubMed: 17106573]

8. Toro L, Stefani E. Calcium-activated $\mathrm{K}^{+}$channels: metabolic regulation. J Bioenerg Biomembr 1991;23:561-76. [PubMed: 1917909]

9. Vergara C, Latorre R, Marrion NV, Adelman JP. Calcium-activated potassium channels. Curr Opin Neurobiol 1998;8:321-9. [PubMed: 9687354]

10. $\mathrm{Xu} \mathrm{W}$, et al. Cytoprotective role of $\mathrm{Ca}^{2+}$ - activated $\mathrm{K}^{+}$channels in the cardiac inner mitochondrial membrane. Science 2002;298:1029-33. [PubMed: 12411707] 
11. Gribkoff VK, et al. Targeting acute ischemic stroke with a calcium-sensitive opener of maxi-K potassium channels. Nat Med 2001;7:471-7. [PubMed: 11283675]

12. Tseng-Crank $\mathrm{J}$, et al. Cloning, expression, and distribution of functionally distinct $\mathrm{Ca}^{2+}$-activated $\mathrm{K}$ + channel isoforms from human brain. Neuron 1994;13:1315-30. [PubMed: 7993625]

13. Jiang $Y$, et al. Crystal structure and mechanism of a calcium-gated potassium channel. Nature 2002;417:515-22. [PubMed: 12037559]

14. Jiang Y, Pico A, Cadene M, Chait BT, MacKinnon R. Structure of the RCK domain from the $E$. coli $\mathrm{K}^{+}$channel and demonstration of its presence in the human BK channel. Neuron 2001;29:593601. [PubMed: 11301020]

15. Magleby KL. Gating mechanism of BK (Slo1) channels: so near, yet so far. J Gen Physiol 2003;121:81-96. [PubMed: 12566537]

16. Niu X, Qian X, Magleby KL. Linker-gating ring complex as passive spring and $\mathrm{Ca}^{2+}$-dependent machine for a voltage- and $\mathrm{Ca}^{2+}$-activated potassium channel. Neuron 2004;42:745-56. [PubMed: 15182715]

17. Horrigan FT, Aldrich RW. Coupling between voltage sensor activation, $\mathrm{Ca}^{2+}$ binding and channel opening in large conductance (BK) potassium channels. J Gen Physiol 2002;120:267-305. [PubMed: 12198087]

18. Tang XD, Santarelli LC, Heinemann SH, Hoshi T. Metabolic regulation of potassium channels. Annu Rev Physiol 2004;66:131-59. [PubMed: 14977399]

19. Tang XD, et al. Haem can bind to and inhibit mammalian calcium-dependent Slo1 BK channels. Nature 2003;425:531-5. [PubMed: 14523450]

20. Jaggar JH, et al. Heme is a carbon monoxide receptor for large-conductance $\mathrm{Ca}^{2+}$-activated $\mathrm{K}^{+}$ channels. Circ Res 2005;97:805-12. [PubMed: 16166559]

21. Schubert R, Nelson MT. Protein kinases: tuners of the $\mathrm{BK}_{\mathrm{Ca}}$ channel in smooth muscle. Trends Pharmacol Sci 2001;22:505-12. [PubMed: 11583807]

22. Hayabuchi Y, Nakaya Y, Matsuoka S, Kuroda Y. Effect of acidosis on $\mathrm{Ca}^{2+}$-activated $\mathrm{K}^{+}$channels in cultured porcine coronary artery smooth muscle cells. Pflügers Arch 1998;436:509-14.

23. Avdonin V, Tang XD, Hoshi T. Stimulatory action of internal protons on Slo1 BK channels. Biophys J 2003;84:2969-80. [PubMed: 12719228]

24. Church J, Baxter KA, McLarnon JG. pH modulation of $\mathrm{Ca}^{2+}$ responses and a $\mathrm{Ca}^{2+}$-dependent $\mathrm{K}^{+}$ channel in cultured rat hippocampal neurones. J Physiol (Lond) 1998;511:119-32. [PubMed: 9679168]

25. Lee KK, Fitch CA, Lecomte JT, Garcia-Moreno EB. Electrostatic effects in highly charged proteins: salt sensitivity of $\mathrm{pK}_{\mathrm{a}}$ values of histidines in staphylococcal nuclease. Biochemistry 2002;41:565667. [PubMed: 11969427]

26. Ye S, Li Y, Chen L, Jiang Y. Crystal structures of a ligand-free MthK gating ring: insights into the ligand gating mechanism of $\mathrm{K}^{+}$channels. Cell 2006;126:1161-73. [PubMed: 16990139]

27. Xia XM, Zeng X, Lingle CJ. Multiple regulatory sites in large-conductance calcium-activated potassium channels. Nature 2002;418:880-4. [PubMed: 12192411]

28. Shi J, et al. Mechanism of magnesium activation of calcium-activated potassium channels. Nature 2002;418:876-80. [PubMed: 12192410]

29. Zeng XH, Xia XM, Lingle CJ. Divalent cation sensitivity of BK channel activation supports the existence of three distinct binding sites. J Gen Physiol 2005;125:273-86. [PubMed: 15738049]

30. Miksovska J, et al. Distant electrostatic interactions modulate the free energy level of QA- in the photosynthetic reaction center. Biochemistry 1996;35:15411-7. [PubMed: 8952493]

31. Bao L, Rapin AM, Holmstrand EC, Cox DH. Elimination of the $\mathrm{BK}_{\mathrm{Ca}}$ channel's high-affinity $\mathrm{Ca}^{2}$ ${ }^{+}$sensitivity. J Gen Physiol 2002;120:173-89. [PubMed: 12149279]

32. Qian X, Niu X, Magleby KL. Intra- and intersubunit cooperativity in activation of BK channels by $\mathrm{Ca}^{2+}$ J Gen Physiol 2006;128:389-404. [PubMed: 17001085]

33. Cox DH, Cui J, Aldrich RW. Allosteric gating of a large conductance Ca-activated $\mathrm{K}^{+}$channel. J Gen Physiol 1997;110:257-81. [PubMed: 9276753]

34. Roosild TP, Miller S, Booth IR, Choe S. A mechanism of regulating transmembrane potassium flux through a ligand-mediated conformational switch. Cell 2002;109:781-91. [PubMed: 12086676] 
35. Dong J, Shi N, Berke I, Chen L, Jiang Y. Structures of the MthK RCK domain and the effect of $\mathrm{Ca}^{2+}$ on gating ring stability. J Biol Chem 2005;280:41716-24. [PubMed: 16227203]

36. Takahashi KI, Copenhagen DR. Modulation of neuronal function by intracellular $\mathrm{pH}$. Neurosci Res 1996;24:109-16. [PubMed: 8929916]

37. Kelly T, Church J. pH modulation of currents that contribute to the medium and slow afterhyperpolarizations in rat CA1 pyramidal neurones. J Physiol (Lond) 2004;554:449-66. [PubMed: 14608014]

38. Filosa JA, Dean JB, Putnam RW. Role of intracellular and extracellular $\mathrm{pH}$ in the chemosensitive response of rat locus coeruleus neurones. J Physiol (Lond) 2002;541:493-509. [PubMed: 12042354]

39. Decanniere C, Van Hecke P, Vanstapel F, Ville H, Geers R. Metabolic response to halothane in piglets susceptible to malignant hyperthermia: an in vivo ${ }^{31}$ P-NMR study. J Appl Physiol 1993;75:955-62. [PubMed: 8226501]

40. Denton JS, McCann FV, Leiter JC. $\mathrm{CO}_{2}$ chemosensitivity in Helix aspersa: three potassium currents mediate pH-sensitive neuronal spike timing. Am J Physiol Cell Physiol 2007;292:C292-304. [PubMed: 16928774]

41. Rothman SM, Olney JW. Excitotoxicity and the NMDA receptor. Trends Neurosci 1987;10:299_ 302.

42. Maingret F, Patel AJ, Lesage F, Lazdunski M, Honore E. Mechano- or acid stimulation, two interactive modes of activation of the TREK-1 potassium channel. J Biol Chem 1999;274:26691-6. [PubMed: 10480871]

43. Brelidze TI, Magleby KL. Protons block BK channels by competitive inhibition with $\mathrm{K}^{+}$and contribute to the limits of unitary currents at high voltages. J Gen Physiol 2004;123:305-19. [PubMed: 14981139]

44. Starkus JG, Varga Z, Schonherr R, Heinemann SH. Mechanisms of the inhibition of Shaker potassium channels by protons. Pflügers Arch 2003;447:44-54.

45. Derst $\mathrm{C}$, et al. The large conductance $\mathrm{Ca}^{2+}$-activated potassium channel (pSlo) of the cockroach Periplaneta americana: structure, localization in neurons and electrophysiology. The European journal of neuroscience 2003;17:1197-212. [PubMed: 12670308]

46. Tammaro P, Smith AL, Hutchings SR, Smirnov SV. Pharmacological evidence for a key role of voltage-gated $\mathrm{K}^{+}$channels in the function of rat aortic smooth muscle cells. Br J Pharmacol 2004;143:303-17. [PubMed: 15326038]

47. Zar, JH. Biostatistical analysis. Prentice Hall; Upper Saddle River, N. J: 1999.

48. Tang XD, et al. Oxidative regulation of large conductance calcium-activated potassium channels. $\mathbf{J}$ Gen Physiol 2001;117:253-74. [PubMed: 11222629]

49. Santarelli LC, Wassef R, Heinemann SH, Hoshi T. Three methionine residues located within the regulator of conductance for $\mathrm{K}^{+}(\mathrm{RCK})$ domains confer oxidative sensitivity to large-conductance $\mathrm{Ca}^{2+}$-activated $\mathrm{K}^{+}$channels. J Physiol (Lond) 2006;571:329-48. [PubMed: 16396928]

50. Long SB, Campbell EB, Mackinnon R. Crystal structure of a mammalian voltage-dependent Shaker family $\mathrm{K}^{+}$channel. Science 2005;309:897-903. [PubMed: 16002581]

51. Guex N, Peitsch MC. SWISS-MODEL and the Swiss-PdbViewer: an environment for comparative protein modeling. Electrophoresis 1997;18:2714-23. [PubMed: 9504803] 


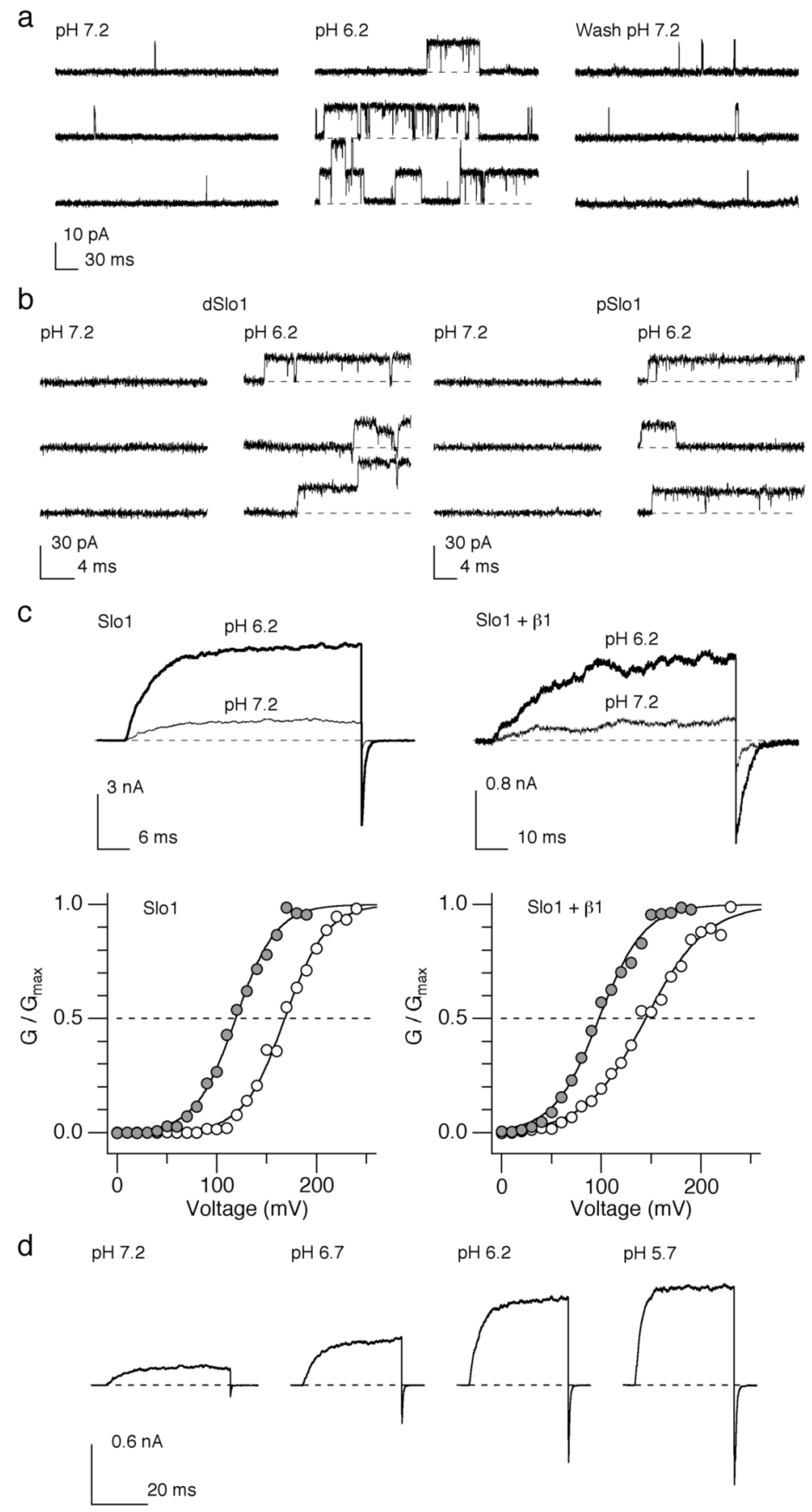

Figure 1.

Low $\mathrm{pH}_{\mathrm{i}}$ enhances the native and recombinant BK channel activity. (a) Representative singlechannel current openings in response to pulses from -80 to $-40 \mathrm{mV}$ from a rat aortic smooth muscle cell at $\mathrm{pH}_{\mathrm{i}}=7.2,6.2$ and after wash at 7.2. (b) Representative openings elicited by pulses from $0 \mathrm{mV}$ to $160 \mathrm{mV}$ in membrane patches from HEK cells expressing Drosophila melanogaster Slo1 (dSlo1; left) and Periplaneta americana Slo1 (pSlo1; right). (c) Representative macroscopic current traces at $\mathrm{pH}_{\mathrm{i}}=7.2$ and 6.2 through by heterologouslyexpressed hSlo1 and hSlo1+ $\beta 1$ channels. The currents were activated by depolarization from $0 \mathrm{mV}$ to $100 \mathrm{mV}(\mathrm{hSlo} 1)$ and $70 \mathrm{mV}(\mathrm{hSlo} 1+\beta 1)$ in the absence of $\mathrm{Ca}^{2+}$, respectively. Normalized $\mathrm{G}-\mathrm{V}$ curves at $\mathrm{pH}_{\mathrm{i}}=7.2$ (open circles) and 6.2 (filled circles) are shown below the 
current traces. The smooth curves represent Boltzmann fits. (d) Currents from hSlo1 channels elicited by pulses from 0 to 100 and then to $-80 \mathrm{mV}$ at the different $\mathrm{pH}_{\mathrm{i}}$ indicated in the absence of $\mathrm{Ca}^{2+}$. 


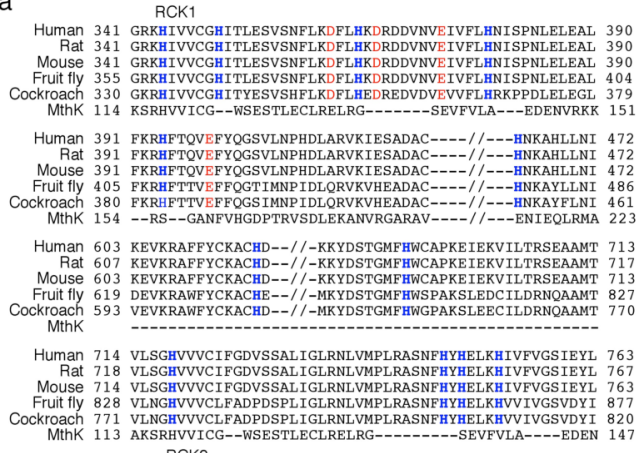

RCK2
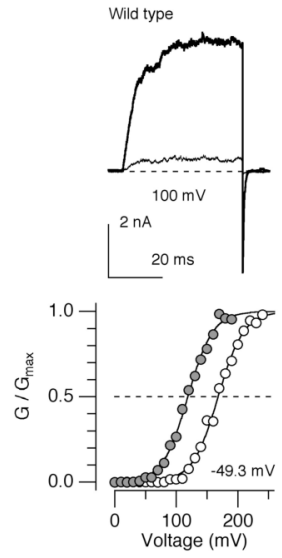

H365R

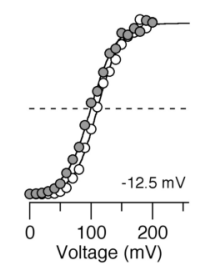

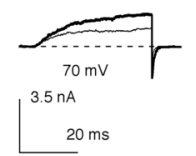

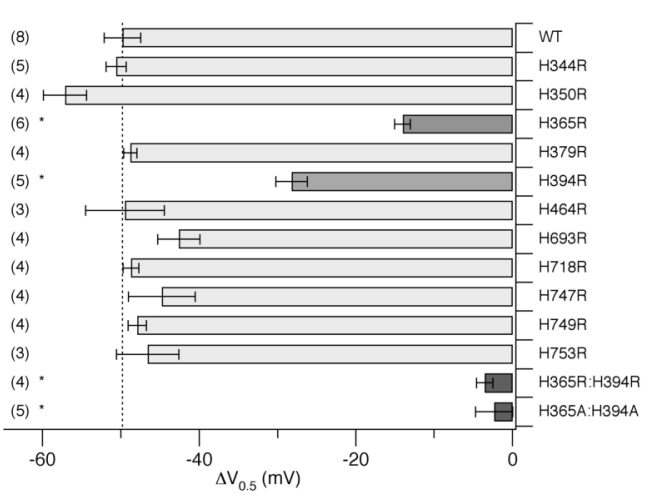

H365R:H394R H365A:H394A
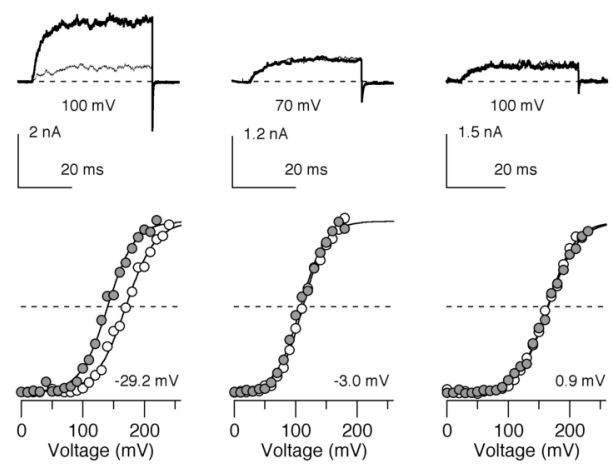

Figure 2.

Mutation of two histidine residues located in the RCK1 domain of hSlo1 abolishes the sensitivity to low $\mathrm{pH}_{\mathrm{i}}$. (a) Sequence alignment of the C-terminal intracellular domains of Slo1 from human (GI:507922), rat (rSlo1, GI:46396068), mouse (GI:18448948), the fruit fly Drosophila melanogaster (GI:115311626), and the American cockroach Periplaneta americana (GI:25991360). The MthK sequence is also shown aligned ${ }^{34}$. Histidine residues conserved among Slo1 are shown in blue. (b) Changes in $\mathrm{V}_{0.5}$ caused by a decrease in $\mathrm{pH}_{\mathrm{i}}$ from 7.2 to 6.2 in the wild-type and mutant channels in the absence of $\mathrm{Ca}^{2+}$ (also see Supplementary Table 1). $* P<0.01$. Error bars represent s.e.m. (c) Representative currents recorded at $\mathrm{pH}_{\mathrm{i}}=7.2$ (thin sweeps) and 6.2 (thick sweeps) for the wild-type and select mutant Slo1 channels in the absence of $\mathrm{Ca}^{2+}$. The currents were elicited by pulses from 0 to the voltages indicated where $\mathrm{G} / \mathrm{G}_{\max }$ is about 0.1 at $\mathrm{pH}_{\mathrm{i}}=7.2$. Normalized $\mathrm{G}-\mathrm{V}$ curves at $\mathrm{pH}_{\mathrm{i}}=7.2$ (open circles) and 6.2 (filled circles) are shown below the current sweeps. The number in each graph represents $\Delta \mathrm{V}_{0.5}$. The smooth curves are Boltzmann fits to the data. 
a

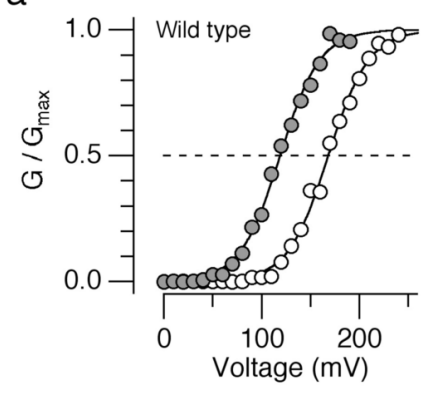

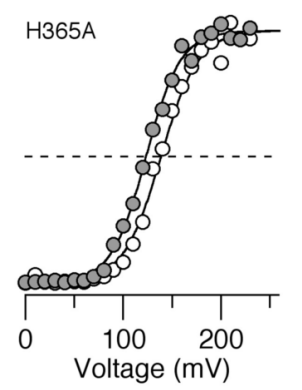

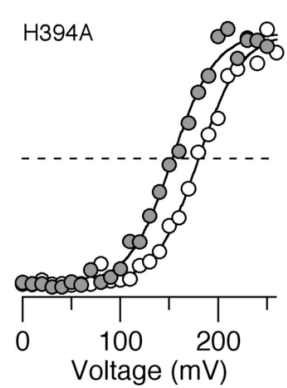

b

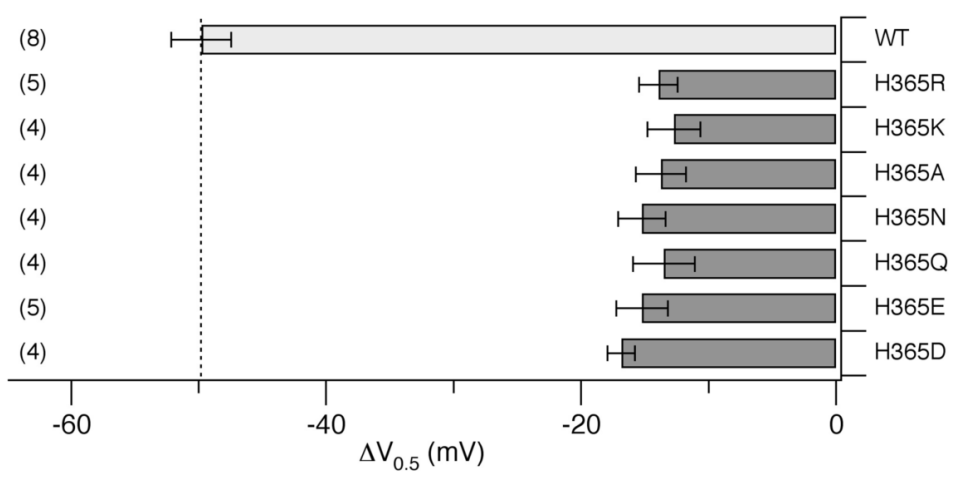

C

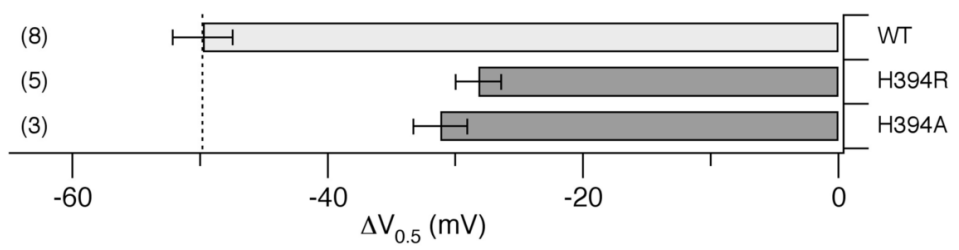

d

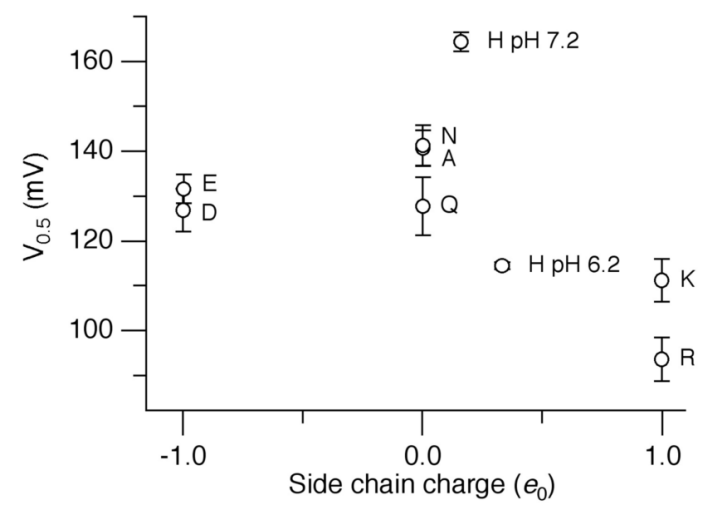

Figure 3.

Mutation of His365 and His394. (a) Representative G-V curves from the wild-type, H365A and His 394 channels at $\mathrm{pH}_{\mathrm{i}}=7.2$ (open circles) and 6.2 (filled circles) in the absence of $\mathrm{Ca}^{2+}$. (b) Mean $\Delta \mathrm{V}_{0.5}$ values caused by lowering $\mathrm{pH}_{\mathrm{i}}$ from 7.2 to 6.2 in the wild-type and the mutant channels with different amino acids at position 365. (c) Mean $\Delta \mathrm{V}_{0.5}$ values caused by lowering $\mathrm{pH}_{\mathrm{i}}$ from 7.2 to 6.2 in the wild-type and the mutant channels with different amino acids at position 394. (d) Mean $\mathrm{V}_{0.5}$ values at $\mathrm{pH}_{\mathrm{i}}=7.2$ in the absence of $\mathrm{Ca}^{2+}$ from the mutant channels with different amino acids at position 365 as a function of the side chain charge status. Arg and Lys are assumed to be fully positively charged and Asp and Glu were assumed to be fully negatively charged. Ala, Asn, and Gln were assumed to have no net charge. The values for the 
wild-type channels at $\mathrm{pH}_{\mathrm{i}}=6.2$ and 7.2 are also shown assuming that the side chain $\mathrm{pK}_{\mathrm{a}}=6.5$. Error bars represent s.e.m. 
a

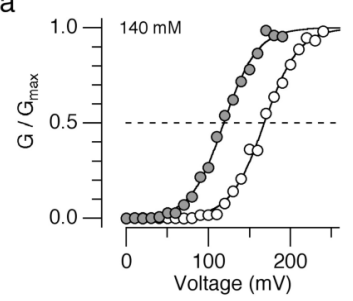

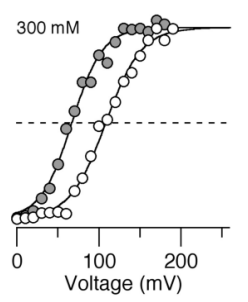
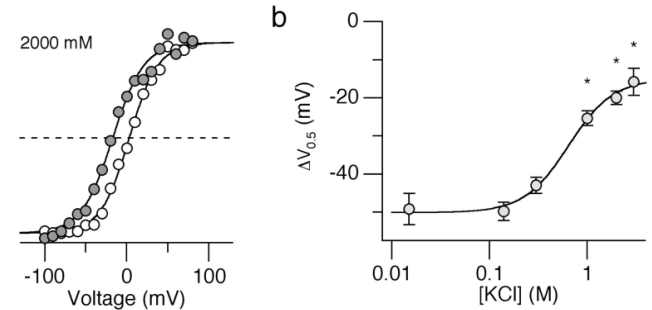

Figure 4.

High ionic strength solutions diminish $\Delta \mathrm{V}_{0.5}$ caused by lowering $\mathrm{pH}_{\mathrm{i}}$ from 7.2 to 6.2 in the absence of $\mathrm{Ca}^{2+}$. (a) Representative G-V curves from the wild-type hSlo1 channels in different concentrations of $\mathrm{KCl}(\mathrm{mM})$. (b) $\Delta \mathrm{V}_{0.5}$ values at different $[\mathrm{KCl}]_{\mathrm{i}}$. The curve represents the Hill equation fit. Error bars represent s.e.m. $\mathrm{n}=3$ to 8 . $* P<0.01$. 
a

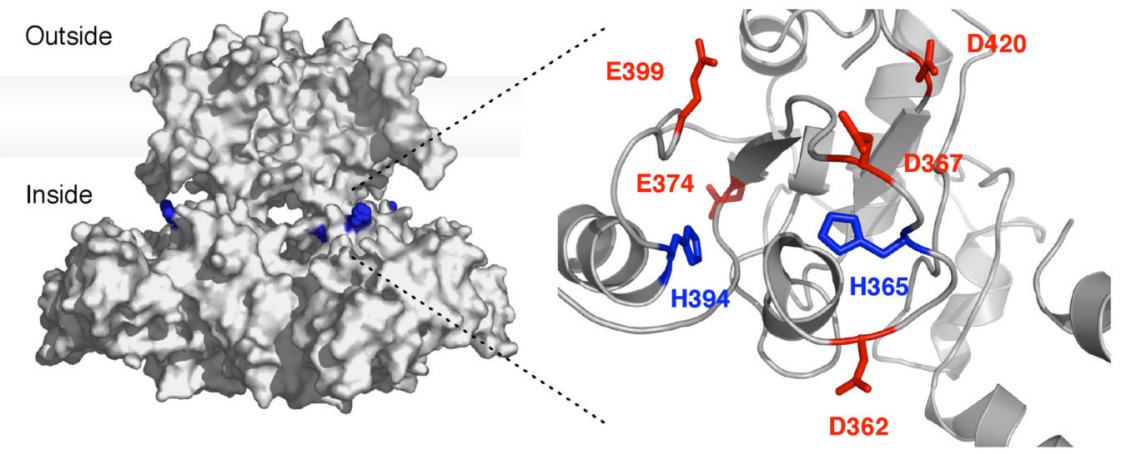

b

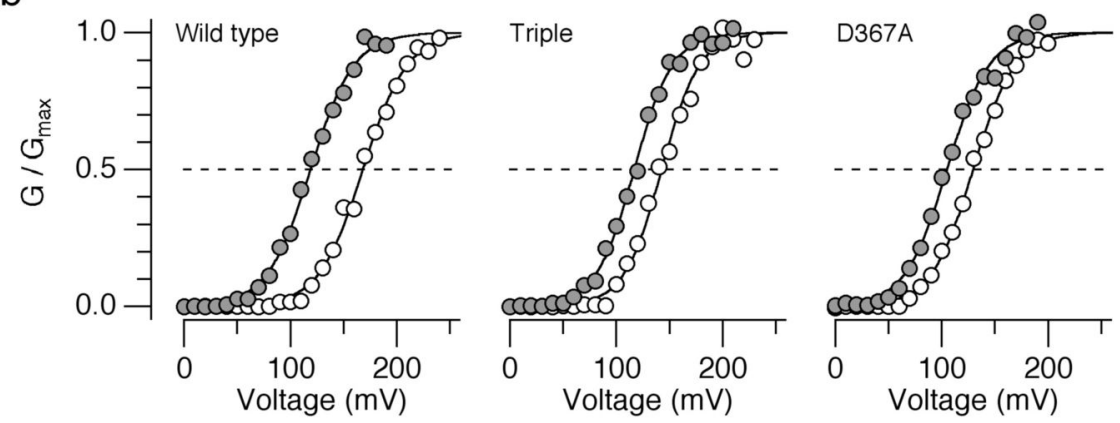

C

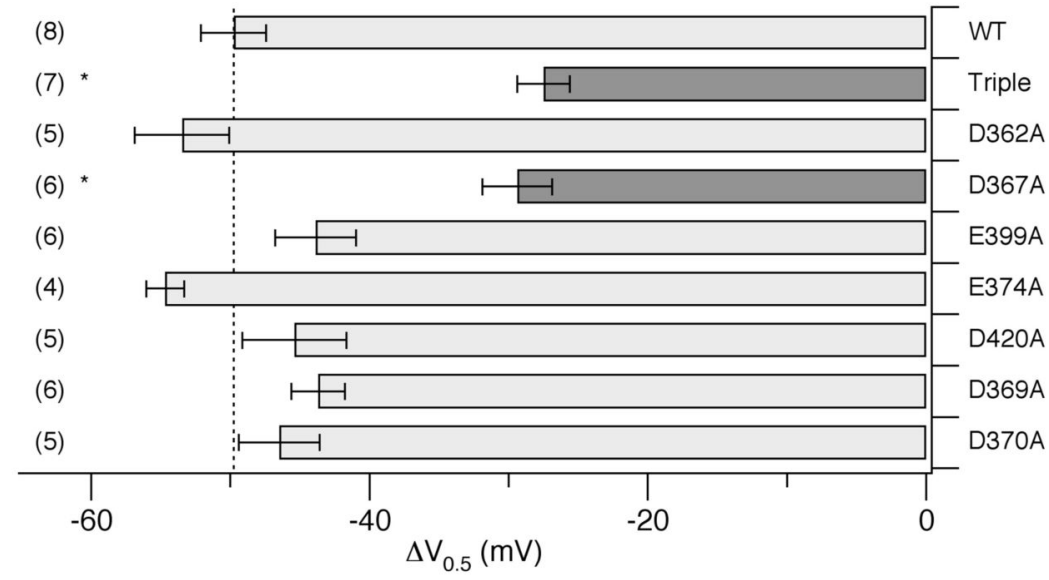

Figure 5.

Mutation of Asp367 diminishes the $\mathrm{pH}_{\mathrm{i}}$ sensitivity. (a) A speculative overall structure of hSlo1 illustrating the locations of His365 and His394 (left) and a homology model of the Slo1 RCK1 domain $(r i g h t)$. The hSlo1 sequence was aligned with those of Kv1.2 (2A79) ${ }^{50}$ and of MthK (1LNQ) and the overall structure (left) was inferred ${ }^{51}$. The homology model of the RCK1 domain (right) was developed for mSlo1 by Latorre and Brauchi ${ }^{7}$. The mSlo1 sequence is identical to that of hSlo1 in the RCK1 domain (see Fig. 2a). The images were prepared with MacPyMOL. (b) Representative G-V curves from the wild-type, D362A:D367A:E399A ("Triple") and D367A channels at $\mathrm{pH}_{\mathrm{i}}=7.2$ (open circles) and 6.2 (filled circles) in the absence 
of $\mathrm{Ca}^{2+}$. (c) Mean $\Delta \mathrm{V}_{0.5}$ values in the wild-type and mutant channels caused by lowering $\mathrm{pH}_{\mathrm{i}}$ from 7.2 to 6.2 (also see Supplementary Table 1). Error bars represent s.e.m. 


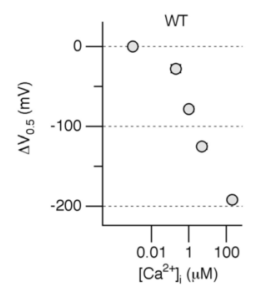

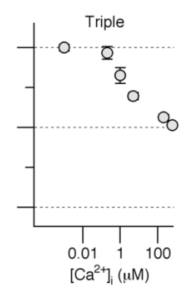

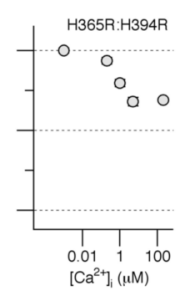

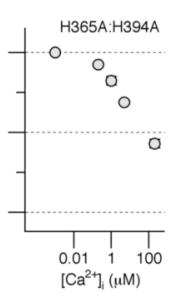

b
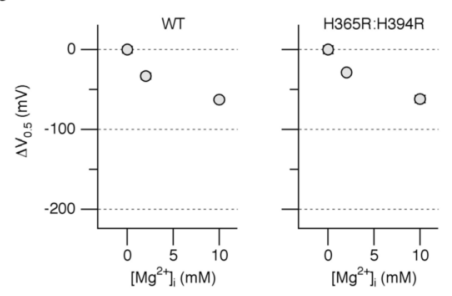

\section{Figure 6.}

Mutation of His 365 and His394 disrupts the $\mathrm{Ca}^{2+}$-dependent activation but fails to alter the $\mathrm{Mg}^{2+}$-dependent activation. (a) $\mathrm{Ca}^{2+}$-dependent activation measured by changes in $\mathrm{V}_{0.5}$ in the wild-type, D362:D367:E399, H365R:H394R, and H365A:H394A channels. For each channel type, the results were normalized to the mean $\mathrm{V}_{0.5}$ value in the virtual absence of $\mathrm{Ca}^{2+} . n=4$ to 9. (b) $\mathrm{Mg}^{2+}$-dependent of activation measured by changes in $\mathrm{V}_{0.5}$ in the wild-type $(n=3)$ and H365R:H394R channels $(n=5)$. Error bars represent s.e.m. 